\title{
Receipt of radiotherapy after mastectomy in women with breast cancer: population-based cohort study in New Zealand
}

Authors: Phyu Mon Latt, ${ }^{1}$ Sandar Tin Tin, ${ }^{1}$ Mark Elwood, ${ }^{1}$ Ross Lawrenson, ${ }^{2}$ Ian Campbell, ${ }^{3}$

Affiliations:

${ }^{1}$ Section of Epidemiology and Biostatistics, School of Population Health, The University of Auckland Tamaki Innovation Campus, Auckland 1072, New Zealand.

${ }^{2}$ National Institute of Demographic and Economic Analysis, The University of Waikato, Hamilton 3240, New Zealand.

${ }^{3}$ Waikato Clinical Campus, The University of Auckland, Hamilton 3240, New Zealand.

Short running title: Receipt of radiotherapy after mastectomy

Corresponding author:

Phyu Mon Latt

Email: plat182@aucklanduni.ac.nz

Phone: +959965089841

\section{Acknowledgements}

This study was funded by the New Zealand Breast Cancer Foundation. Phyu Mon Latt was supported by the NZAID Scholarship for her Master’s studies at the University of Auckland. We thank the Auckland Breast Cancer Study Group, Waikato Breast Cancer Trust, Waikato Bay of Plenty Division of the Cancer Society, and the Ministry of Health for maintaining and providing the required data, and Drs Erica Whineray-Kelly and Glenys Round for advice. 


\section{Abstract}

Purpose: To investigate the receipt of post-mastectomy radiotherapy (PMRT) in breast cancer patients in New Zealand for whom radiotherapy is strongly recommended in current clinical guidelines.

Method: This study involved all women who were diagnosed with primary invasive breast cancer in two health regions, had undergone a mastectomy and met the "strong recommendation" criteria for PMRT based on New Zealand National Guidelines. We performed logistic regression analyses to identify demographic and clinical factors associated with the receipt of PMRT.

Results: Of the 1455 patients with stage II to III cancers included in this analysis, 1195 (82\%) received radiotherapy. The receipt of PMRT decreased with increasing age, and was significantly lower in rural residents, Māori and Pacific women, those with more co-morbidity, those who received primary cancer care in a public facility, and those diagnosed with stage III cancer. Although not significant, the receipt was also lower in patients who resided in more deprived neighbourhood, and those with comorbidities. The findings restricted to stage III patients $(n=1325)$, and to those diagnosed since $2010(n=422)$, after the current guidelines were published, were very similar to the whole cohort.

Conclusion: Disparities exist in the receipt of PMRT in New Zealand, underscoring the need for a greater equity focus in management of breast cancer.

Keywords - Breast cancer, utilization, radiotherapy, mastectomy 


\section{Introduction}

Post-mastectomy radiotherapy (PMRT) reduces the risk of loco-regional recurrence and improves survival in appropriately selected women with breast cancer. ${ }^{1-3}$ In a large meta-analysis of randomized trials, PMRT in node positive women reduced 10-year loco-regional recurrence as a first event from $26 \%$ to $8.1 \%$ and resulted in a relative risk of breast cancer death of $0.84 .{ }^{4}$ In New Zealand, radiation treatment after a mastectomy is strongly recommended for patients whose tumor size is more than $5 \mathrm{~cm}$, or have four or more positive axillary lymph nodes, or have a close surgical margin after mastectomy, in the National Guidelines published in $2009 .{ }^{5}$ Indications for PMRT have steadily broadened to lower the risk of recurrence over the last 2 decades, However, even in the highrisk groups, not all patients receive the recommended treatment. ${ }^{6}$

The receipt of radiotherapy after a mastectomy can be influenced by a number of factors, including patient demographics, tumor characteristics and environmental factors. ${ }^{7-16}$ Demographic factors such as race, age at diagnosis, urban/ rural difference and socio-economic conditions, and tumor characteristics such as stage have been described as factors influencing the receipt of radiation therapy after a mastectomy. ${ }^{7-16}$ Distance to the radiation facility has been shown to reduce the receipt of the treatment in a variety of settings, ${ }^{8-13,16}$ but the results are not consistent. These findings from other countries may or may not be applicable to the New Zealand context.

We, therefore, investigated the receipt of PMRT in breast cancer patients in New Zealand for whom radiotherapy would normally be strongly recommended, to identify factors that have affected or been associated with the receipt of this treatment. This group was chosen as the New Zealand guidelines are similar to those in other countries, and the indications for use of PMRT in lower risk women are less clear. 


\section{Methods}

Study Database: This population-based cohort study utilized the data from the Auckland Breast Cancer Register (ABCR) and the Waikato Breast Cancer Register (WBCR). The ABCR and WBCR are comprehensive regional population-based databases, and use the same core data. The ABCR has captured almost all newly-diagnosed breast cancer cases in the Auckland, Counties Manukau, Waitemata District Health Board (DHB) regions since 2000 and the WBCR has recorded almost all patients in the Waikato DHB region from 1991 onward. The completeness of the WBCR has been checked against the legally-mandated National Cancer Registry and was found to be $99 \%$ complete. ${ }^{17}$ The ABCR is also complete with $1 \%$ loss to follow up. ${ }^{18}$ The registers recorded patients' National Health Index (NHI) number (a unique patient identifier), demographic details, disease factors and treatment factors. Both databases contain more comprehensive and accurate information than national data sources. ${ }^{17-19}$

The registers are regularly linked to the National Cancer Registry, which contains information about all malignant tumors first diagnosed in New Zealand (except basal cell and squamous cell tumors of the skin), and the Mortality Collection, which contains information about all deaths registered in the country, using the NHI number. We also linked the data to the National Minimum Dataset, which contains information about patients discharged from all public and over 90\% of private hospitals in New Zealand, to collect information on comorbidities.

Study sample: We identified all patients who were diagnosed with breast cancer and had undergone a mastectomy with the date of diagnosis from $1^{\text {st }}$ January 2000 to $30^{\text {th }}$ June 2014 in the ABCR, and from $1^{\text {st }}$ January 1991 to $30^{\text {th }}$ June 2014 in the WBCR ( $\mathrm{N}=16111)$. We excluded patients who received a mastectomy not as part of their primary treatment or who received a mastectomy due to local recurrence, those without axillary surgery, those who received chemotherapy prior to mastectomy for down-staging of the disease, those with non-invasive breast cancer, those with metastatic breast cancer, those with a second new cancer, and male patients. Of the 6654 women identified, 1455 patients (22\%) met the "strong recommendation" criteria for PMRT set by the New Zealand Guidelines ${ }^{5}$ based on tumor size (more than $5 \mathrm{~cm}$ ) and number of lymph nodes (four or more). Eligibility based on the margin size was not considered as this information was not available.

Variables of interest: The main study outcome was the receipt of PMRT. The potential predictors of interest include: patient demographics such as age, ethnicity and area of residence, disease characteristics such as tumor stage at diagnosis, grade, histology, hormone receptor status, comorbidity and health care facility type where primary cancer treatment was undertaken. For staging, Tumor-Node-Metastasis (TNM) classification by American Joint Committee on Cancer Staging (7th Edition) was used. The health domicile codes, which represent patients' residential addresses, were categorized as urban (main urban area, satellite urban community, and rural area with high urban influence), and rural areas (others) based on Statistics New Zealand's Urban/ Rural Profile. ${ }^{20}$ Main urban areas are centered on a city or main urban centre and have a minimum population of 30,000; satellite urban communities are areas where $20 \%$ or more of the resident employed population work in a main urban area; and rural areas with high urban influence are areas where a significant proportion of the resident employed population work in a main urban area. The domicile codes were also mapped on to the 2006 New Zealand Deprivation Index (NZDep) and the degree of neighborhood deprivation was assessed using a one-to-ten decile scale with decile ten the most deprived, and decile one the least. ${ }^{21}$ A C3 index score was used to measure patients' comorbidity. It is a cancer-specific index of comorbidity based on the presence of 42 chronic conditions recorded in the National 
Minimum Dataset for a period of five years prior to the diagnosis of cancer. ${ }^{22}$ Each condition was weighted by its impact on one-year non-cancer mortality in a cancer cohort, and the weights were then summed to get a final comorbidity score. This information was available for patients registered from 2000 onwards only.

Data analysis: We restricted our main analysis to the 1455 patients who were diagnosed with stages II to III breast cancer between 1991 and 2014 and for whom PMRT was 'strongly recommended' in the guidelines. We compared demographic and clinical profiles between patients who received PMRT and those who did not by using chi-square tests. We then performed univariate and multivariate logistic regression analyses to identify factors associated with the receipt of PMRT. We undertook similar analyses by restricting analyses to patients diagnosed with stage III breast cancer only $(n=1325)$. We performed a sensitivity analysis by restricting analyses to the 422 patients who were registered from 2010 onward (after the most recent guidelines were published). 


\section{Results}

Of the 1455 breast cancer patients who were diagnosed between 1991 and 2014 and met the "strong recommendation” criteria for PMRT, 1195 (82\%) received radiotherapy, and 260 (18\%) did not (Table 1). The receipt of PMRT decreased substantially with age from the youngest to the oldest category. The odds ratio, after control for demographic, clinical and pathological factors, for those aged 80+ was 0.19, with 95\% confidence interval (CI), 0.12-0.32 compared to middle-aged patients (50-59). Māori women were less likely to receive PMRT than New Zealand European women (adjusted OR 0.60, 95\% CI 0.40-0.91), as were Pacific women (adjusted OR 0.58, 95\% CI 0.36 - 0.95). Receipt of PMRT tended to decrease in groups with increasing social deprivation although the trend was not regular or significant (overall p-value 0.09), Rural residence was associated with a lower receipt of PMRT (adjusted OR: 0.65; 95\% CI, 0.41-1.00). Breast cancer patients who received primary cancer care (mainly surgical treatment) at the private facility were more likely to receive PMRT than those at the public health facilities (adjusted OR: 1.73, 95\% CI, 1.20-2.49). After control of other factors, the use in the two regions was similar.

Regarding clinical factors, the receipt of PMRT was significantly lower in patients with hormone receptor negative tumors, and tended to be lower in those with stage II and with well differentiated tumors (Table 1). The receipt of PMRT was much lower in those with more comorbidity, assessed by higher C3 index scores.

A further analysis was restricted to patients with stage III breast cancer, as the recommendations for PMRT are more generally accepted in this group. Demographic factors had similar or stronger associations in stage III patients, with significantly less PMRT use in patients who were older, Māori or Pacific ethnicity, and had public rather than private health care (Table 2). The associations with clinical and pathological factors were comparable to those in the larger cohort, but weaker, as expected as the range is narrower; however, PMRT usage was lower in patients with receptor negative tumors.

As the current guidelines for breast cancer treatment were published in 2009, further analyses were based on patients diagnosed from 2010 onwards as a sensitivity test to see if the overall results applied to this subgroup. The findings were similar, not suggesting any substantial changes, although, with the smaller sample size, some associations were no longer significant (Table 3). The proportion of patients getting PMRT was 81\% (832/1033) from 1991 to 2009, and $86 \%$ (363/422) in 2010 to 2014 ( $\mathrm{p}=0.01)$. 


\section{Discussion}

We found that only $82 \%$ of patients who met the "strong recommendation" criteria for PMRT (based on tumor size and number of lymph nodes involved) received the treatment. The receipt of PMRT was influenced by a number of demographic factors such as age, ethnicity, area of residence (urban/rural), and health care facility type (public/private). Māori and Pacific patients were significantly less likely to receive PMRT, even after control of other factors including social deprivation. In addition, clinical factors such as hormone receptor status and comorbidity affected the use of PMRT.

This study is based on the data from two prospectively maintained population-based registers that contained comprehensive information about patients diagnosed with primary breast cancer. Linkage to the national databases enabled the study to ascertain information on cause of death and on associated comorbidities. There may be misclassification in identifying patients who were strongly indicated for PMRT as information on the size of tumor margin, a criterion used in the guidelines for recommendation of PMRT, was not available. Particularly, this analysis may have excluded some patients with stage I, who met the "strong recommendation" criteria due to involved margins. We were not able to assess the effect of some potentially important factors such as smoking, alcohol or body mass index, as such information was not available. Some findings may be affected by data inaccuracy, for example, information on ethnicity recorded in the Auckland Registry is based on that linked to the National Health Index, which may result in under-counting of Māori population and under-estimation of associations. The New Zealand deprivation score, NZDep 2006, used in the analyses measures area-level deprivation and may not fully reflect an individual's actual socioeconomic status although it has been validated previously. ${ }^{23}$

Clinical guidelines are not standards of practice, and are designed to clarify the appropriate treatment for patients who show certain characteristics. Clinicians are expected to be aware of the guidelines, but not to apply them automatically, and need to take into account the individual situation of each patient. There are a number of possible contraindications to PMRT, including connective tissue diseases like systemic lupus erythematosus (SLE), or severe respiratory disease, or inability to lie flat or still or with the arm abducted. Further, the actual utilization of radiotherapy depends on a shared decision between the doctor and the patient, and patient choice may influence utilization. However, there was limited information in the dataset about whether the receipt or non-receipt of PMRT was due to the doctor's choice or patients' choice.

The general impression from the clinical factors considered is that even though radiotherapy is strongly recommended in the guidelines for all the patients in this analysis, clinical factors which confer a higher risk of recurrence or death from breast cancer result in a greater utilization of radiotherapy; such as stage III disease, poor differentiation. This suggests that in patients without these high-risk factors either clinicians advocate with less enthusiasm, or do not advocate radiotherapy despite it being recommended in the guidelines, or the patient decides that they do not want radiotherapy. Both situations may be rationalized on the basis that in lower risk patients, it is likely that the potential benefits of radiotherapy are lower while the disadvantages of the treatment remain similar, so that the likely risk-benefit equation is less favorable to treatment. However, it could be asked whether such considerations could be taken into account to a greater extent in future guidelines, so that there would be less variation between the guideline recommendation and actual clinical practice For example, is it appropriate for the guidelines to recommend radiotherapy for patients over the age of 80 , as it is known that the risk of locoregional 
recurrence tends to decrease with increasing age, ${ }^{24}$ and older women often have co-morbidities that may be a relative contraindication to PMRT (eg chronic obstructive airway disease, or severe ischemic heart disease). Competing risks for life expectancy also increase with age, so that benefits of treatment are less for older women. This analysis shows that in reality, radiotherapy is much less used in these patients.

The evidence for the benefits of PMRT has increased over the period of this study, with major trials reported in 1997 and $1999^{1-3}$ and a major overview in 2005. ${ }^{1}$ The New Zealand guidelines were published in 2009, although many breast cancer clinicians were involved or aware of earlier drafts and discussions. Despite this strengthening of published evidence, features associated with receipt of PMRT did not change greatly over this period.

Overall, this analysis on a population-based series of breast cancer patients shows that $18 \%$ of patients for whom radiotherapy is recommended in current clinical guidelines, do not receive this treatment. This situation may compare well to other estimates, for example on New South Wales, Australia, data it was estimated that optimally $82 \%$ of breast cancer patients should get radiotherapy, while $54 \%$ received it. ${ }^{25,26}$ Some of these variations may be explicable on the basis that radiotherapy is used by patients with clinical indications conferring a higher risk of poor outcome and greater potential benefits from radiotherapy. This does suggest that clinicians in practice are more cautious in their recommendations for radiotherapy than the guideline criteria would indicate. This may be an acceptable situation, but further work on the criteria for recommendation of radiotherapy, and the criteria for acceptance of radiotherapy by the patient, would be needed to understand this process further. Some information on referrals and patient choice was recorded, but this information may be questionable. It shows that of the 260 patients not receiving radiotherapy, 131 (50\%) did not get a referral to a radiation oncologist (but whether no referral was offered, or the patient declined to be referred is unknown). A further 11 (4\%) had a referral but did not attend, and 65 (25\%) declined the offer of radiotherapy. Thus 46 patients (18\%) were offered radiotherapy, apparently accepted it initially, but did not receive the treatment. However, we feel that this information should not be accepted without further validation.

The variations in radiotherapy utilization in terms of demographic factors, shown as substantial and significant variations in analyses which have taken into account the relevant clinical factors, are less understandable and seem less acceptable. The diminished radiotherapy uptake with increasing age has been shown in several studies, 7,9,12,14,15 and may be explicable on the basis that the potential benefits to individual patients are smaller, and the potential risks and threats to quality of life greater in older patients. This may apply to patients at more advanced ages, but does not readily explain why the utilization of radiotherapy, for example, in stage III patients aged 5059 is lower than the utilization in patients under 40 years of age.

Similarly, it is difficult to understand why utilization is lower in Māori and Pacific women than in European women, given that key clinical factors such as staging has been taken into account. The tendency for reduced utilization in more deprived social groups, and the lower utilization in rural resident patients, along with this ethnic variation, suggests that utilization depends on economics, access, and other social factors, in addition to recognized clinical indications. This, in turn, suggests that further effort should be made to understand these factors and take actions to reduce the impact, which would include attention to the economic circumstances, opportunities for travel, and competing demands in jobs and family care responsibilities, which affect cancer patients, particularly those with more disadvantaged social circumstances. The lower uptake of radiotherapy by rural women has potential implications for use of radiotherapy in other breast cancer situations. Current techniques require women 
to attend a major center 5 days a week for 3 to 5 weeks for treatment. This poses challenges for women who live some distance from these centers, and are potentially forced to travel, or live away from family, friends and other home support during treatment.

Whether patient choice factors are important in relating to the low utilization of radiotherapy by Māori and Pacific women is clearly an important question which has hardly been explored. The contrast to these findings is the higher utilization in patients treated in private facilities; whether this relates to any difference in the way radiotherapy is advocated to such patients, or relates to patient choice, or is a reflection of the likely easier economic circumstances of such patients in being able to accept radiotherapy, would be worthy of further exploration.

To conclude, in this population-based series of stage II-III breast cancer patients for whom PMRT is recommended in the current clinical guidelines, only $82 \%$ actually received this treatment. Patients with features of more advanced or aggressive disease tended to receive radiotherapy more often, which may be appropriate. But after adjusting for clinical and pathological features, demographic factors such as age, ethnicity, deprivation status, residing area (urban/rural), and public/private health care status had significant effects on the receipt of radiotherapy. Utilization patterns did not show substantial changes in more recent years, after publication of the guidelines. 


\section{References}

[1] Early Breast Cancer Trialists' Collaborative Group. Effects of radiotherapy and of differences in the extent of surgery for early breast cancer on local recurrence and 15-year survival: an overview of the randomised trials. Lancet 2005; 366(9503):2087-2106.

[2] Overgaard M, Hansen PS, Overgaard J, Rose C, Andersson M, Bach F, et al. Postoperative radiotherapy in high-risk premenopausal women with breast cancer who receive adjuvant chemotherapy. Danish Breast Cancer Cooperative Group 82b Trial. N Engl J Med 1997 Oct; 337(14): 949-955.

[3] Overgaard M, Jensen M, Overgaard J, Hansen P, Rose C, Andersson M, et al. Postoperative radiotherapy in high- risk postmenopausal breast- cancer patients given adjuvant tamoxifen: Danish Breast Cancer Cooperative Group DBCG 82c randomized trial. The Lancet 1999;353(9165):1641-1648.

[4] EBCTCG (Early Breast Cancer Trialists' Collaborative Group), McGale P, Taylor C, Correa C, Cutter D, Duane F, et al. Effect of radiotherapy after mastectomy and axillary surgery on 10-year recurrence and 20-year breast cancer mortality: meta-analysis of individual patient data for 8135 women in 22 randomized trials. Lancet 2014 Jun 21;383(9935):2127-2135.

[5] Ministry of Health. Management of Early Breast Cancer: Evidence-based Best Practice Guideline.

Wellington: New Zealand Guidelines Group (NZGG); 2009; Available at:

http://www.health.govt.nz/publication/management-early-breast-cancer-evidence-based-best-practice-guideline

[6] Tin Tin S, Elwood JM, Lawrenson R, Campbell I, Harvey V, Seneviratne S. Differences in Breast Cancer Survival between Public and Private Care in New Zealand: Which Factors Contribute? PLoS One 2016 April; 11(4): e0153206.

[7] Dragun AE, Huang B, Tucker TC, Spanos WJ. Disparities in the application of adjuvant radiotherapy after breast-conserving surgery for early stage breast cancer: impact on overall survival. Cancer 2011 Jun; 117(12): 2590-2598.

[8] Meden T, St John-Larkin C, Hermes D, Sommerschield S. MSJAMA. Relationship between travel distance and utilization of breast cancer treatment in rural northern Michigan. JAMA 2002 Jan; 287(1): 111.

[9] Wheeler SB, Kuo TM, Durham D, Frizzelle B, Reeder-Hayes K, Meyer AM. Effects of distance to care and rural or urban residence on receipt of radiation therapy among North Carolina Medicare enrollees with breast cancer. N C Med J 2014 Jul-Aug; 75(4): 239-246.

[10] Athas WF, Adams-Cameron M, Hunt WC, Amir-Fazli A, Key CR. Travel distance to radiation therapy and receipt of radiotherapy following breast-conserving surgery. J Natl Cancer Inst 2000 Feb; 92(3): 269-271.

[11] Tyldesley S, McGahan C. Utilization of radiotherapy in rural and urban areas in British Columbia compared with evidence-based estimates of radiotherapy needs for patients with breast, prostate and lung cancer. Clin Oncol (R Coll Radiol) 2010 Sep; 22(7): 526-532.

[12] Fong A, Shafiq J, Saunders C, Thompson AM, Tyldesley S, Olivotto IA, et al. A comparison of surgical and radiotherapy breast cancer therapy utilization in Canada (British Columbia), Scotland (Dundee), and Australia (Western Australia) with models of "optimal" therapy. Breast 2012 Aug; 21(4): 570-577.

[13] Sharma D. Does increased geographical distance to a radiation therapy facility act as a barrier to seeking treatment? Australian Medical Student Journal 2015; Available at http://www.amsj.org/archives/4285.

[14] Hershman DL, Buono D, McBride RB, Tsai WY, Joseph KA, Grann VR, et al. Surgeon characteristics and receipt of adjuvant radiotherapy in women with breast cancer. J Natl Cancer Inst 2008 Feb; 100(3): 199-206.

[15] Yeboa DN, Xu X, Jones BA, Soulos P, Gross C, Yu JB. Trend in Age and Racial Disparities in the Receipt of Postlumpectomy Radiation Therapy for Stage I Breast Cancer: 2004-2009. Am J Clin Oncol 2014 May. 
[16] Wheeler SB, Carpenter WR, Peppercorn J, Schenck AP, Weinberger M, Biddle AK.

Structural/organizational characteristics of health services partly explain racial variation in timeliness of radiation therapy among elderly breast cancer patients. Breast Cancer Res Treat 2012 May; 133(1): 333-345.

[17] Seneviratne S, Campbell I, Scott N, Shirley R, Peni T, Lawrenson R. Accuracy and Completeness of the New Zealand Cancer Registry for Staging of Invasive Breast Cancer. Cancer Epidemiol 2014 Oct; 38(5): 638644.

[18] Neave L, Harvey V, Benjamin C, Thompson P, Pellett O, Whitlock J, et al. The Auckland Breast Cancer Register: a special project of the Auckland Breast Cancer Study Group. N Z Med J 2003 Oct; 116(1184): U648.

[18] Gurney J, Sarfati D, Dennett E, Koea J. The completeness of cancer treatment data on the National Health Collections. N Z Med J 2013 Aug; 126(1381): 69-74.

[20] Statistics New Zealand. New Zealand: Urban/Rural Profile. Wellington: Statistics New Zealand; 2007; Available at: http://www.stats.govt.nz/browse_for_stats/Maps_and_geography/Geographic-areas/urban-ruralprofile-update.aspx

[21] Salmond C, Crampton P, Atkinson J. NZDep2006: Index of Deprivation. Wellington: Department of Public Health, University of Otago; 2007; Available at; http://www.otago.ac.nz/wellington/departments/publichealth/research/hirp/otago020194.html

[22] Sarfati D, Gurney J, Stanley J, Salmond C, Crampton P, Dennett E, et al. Cancer-specific administrative data-based comorbidity indices provided valid alternative to Charlson and National Cancer Institute Indices. J Clin Epidemiol 2014 May; 67(5): 586-595.

[23] Salmond CE, Crampton P. Development of New Zealand's deprivation index (NZDep) and its uptake as a national policy tool. Can J Public Health 2012 May; 103(8 Suppl 2): S7-11.

[24] Kong I, Narod SA, Taylor C, Paszat L, Saskin R, Nofech-Moses S, et al. Age at diagnosis predicts local recurrence in women treated with breast-conserving surgery and postoperative radiation therapy for ductal carcinoma in situ: a population-based outcomes analysis. Curr Oncol 2014 Feb; 21(1): e96-e104.

[25] Batumalai V, Shafiq J, Gabriel G, Hanna TP, Delaney GP, Barton M. Impact of radiotherapy underutilisation measured by survival shortfall, years of potential life lost and disability-adjusted life years lost in New South Wales, Australia. Radiother Oncol 2018;(18):10.

[26] Delaney G, Barton M, Jacob S. Estimation of an optimal radiotherapy utilization rate for breast carcinoma: a review of the evidence. Cancer 2003; 98(9):1977-1986. 
Table 1 Sample characteristics, univariate and multivariate analyses by the receipt of PMRT among stages II and III breast cancer patients

\begin{tabular}{|c|c|c|c|c|c|c|}
\hline Characteristics & Total Sample & Received RT & Did not receive $R T$ & $\begin{array}{l}\text { Univariate Analysis } \\
\text { Crude OR (95\% CI) }\end{array}$ & $\begin{array}{l}\text { Multivariate Analysis }{ }^{1} \\
\text { Adjusted OR (95\% CI) }\end{array}$ & $\begin{array}{c}\text { p-value } \\
\text { (Multivariate Analyses) }\end{array}$ \\
\hline Total & 1455 & $1195(82 \%)$ & $260(18 \%)$ & & & \\
\hline \multicolumn{7}{|l|}{ Age Group } \\
\hline$<40$ & 176 & 155 (88\%) & $21(12 \%)$ & $1.38(0.80-2.36)$ & $1.56(0.89-2.73)$ & $<.0001$ \\
\hline $40-49$ & 408 & 354 (87\%) & $54(13 \%)$ & $1.22(0.81-1.83)$ & $1.20(0.79-1.83)$ & \\
\hline $50-59$ & 350 & 295 (84\%) & $55(16 \%)$ & 1 & 1 & \\
\hline $60-69$ & 247 & 205 (83\%) & $42(17 \%)$ & $0.91(0.59-1.41)$ & $0.92(0.59-1.45)$ & \\
\hline $70-79$ & 164 & 129 (79\%) & 35 (21\%) & $0.69(0.43-1.10)$ & $0.67(0.41-1.09)$ & \\
\hline $80+$ & 110 & $57(52 \%)$ & $53(48 \%)$ & $0.20(0.13-0.32)$ & $0.19(0.12-0.32)$ & \\
\hline \multicolumn{7}{|l|}{ Ethnicity } \\
\hline European & 999 & 831 (83\%) & $168(17 \%)$ & 1 & 1 & 0.02 \\
\hline Māori & 181 & $136(75 \%)$ & $45(25 \%)$ & $0.61(0.42-0.89)$ & $0.60(0.40-0.91)$ & \\
\hline Pacific & 132 & $101(77 \%)$ & $31(23 \%)$ & $0.66(0.43-1.02)$ & $0.58(0.36-0.95)$ & \\
\hline Others & 143 & 127 (89\%) & $16(11 \%)$ & $1.61(0.93-2.77)$ & $1.15(0.64-2.04)$ & \\
\hline \multicolumn{7}{|l|}{ NZ Deprivation Codes } \\
\hline NZDep 1 to 2 (least deprived) & 278 & $250(90 \%)$ & $28(10 \%)$ & 1 & 1 & 0.09 \\
\hline NZDep 3 to 6 & 517 & 420 (81\%) & 97 (19\%) & $0.49(0.31-0.76)$ & $0.59(0.37-0.96)$ & \\
\hline $\begin{array}{l}\text { NZDep } 7 \text { to } 10 \text { (most } \\
\text { deprived) }\end{array}$ & 660 & $525(80 \%)$ & $135(20 \%)$ & $0.44(0.28-0.67)$ & $0.63(0.39-1.02)$ & \\
\hline \multicolumn{7}{|l|}{ Urban/Rural } \\
\hline Urban & 1271 & $1061(83 \%)$ & $210(17 \%)$ & 1 & 1 & 0.05 \\
\hline Rural & 184 & 134 (73\%) & $50(27 \%)$ & $0.53(0.37-0.76)$ & $0.65(0.41-1.00)$ & \\
\hline \multicolumn{7}{|l|}{ Public/Private } \\
\hline Public & 987 & 774 (78\%) & $213(22 \%)$ & 1 & 1 & 0.003 \\
\hline Private & 468 & $421(90 \%)$ & 47 (10\%) & $2.47(1.76-3.45)$ & $1.73(1.20-2.49)$ & \\
\hline \multicolumn{7}{|l|}{ Register } \\
\hline Auckland & 1109 & 927 (84\%) & $182(16 \%)$ & 1 & 1 & 0.7 \\
\hline Waikato & 346 & 268 (77\%) & 78 (23\%) & $0.67(0.50-0.91)$ & $0.93(0.63-1.38)$ & \\
\hline
\end{tabular}


Stage

\section{Grade}

1 (well-differentiated)

3 (poorly-differentiated)

$$
83(76 \%)
$$

\section{Histolog}

Ductal

Lobular

Others

880 (81\%)

$201(19 \%)$

1

$1.55(0.89-2.70)$

\section{ER/PR Status}

ER/PR Both positive

ER or PR positive

ER/PR both negative

\section{C3 index}

0 (no comorbid conditions)

1

2

3 (maximum)

1

$101 \quad 86(85 \%) \quad 15(15 \%) \quad 0.99(0.56-1.75)$

$68 \quad 45(66 \%) \quad 23(34 \%) \quad 0.34(0.20-0.57)$

Missing/Unknown

Note: Regarding C3 index, linkage to the hospital discharge data was done only for patients registered 2000 onward which resulted in high number of missing values in C3 index; it was not included in the multivariate analysis. 
Table 2 Sample characteristics, univariate and multivariate analyses by the receipt of PMRT among stage III breast cancer patients

\begin{tabular}{|c|c|c|c|c|c|c|}
\hline Characteristics & Total Sample & Received RT & Did not receive $R T$ & $\begin{array}{l}\text { Univariate Analysis } \\
\text { Crude OR }(95 \% \mathrm{CI})\end{array}$ & $\begin{array}{l}\text { Multivariate Analysis }^{1} \\
\text { Adjusted OR }(95 \% \mathrm{CI})\end{array}$ & $\begin{array}{c}\text { p-value } \\
\text { (Multivariate Analyses) }\end{array}$ \\
\hline Total & 1325 & $1094(83 \%)$ & $231(17 \%)$ & & & \\
\hline \multicolumn{7}{|l|}{ Age Group } \\
\hline $40-49$ & 367 & $319(87 \%)$ & $48(13 \%)$ & $1.19(0.77-1.83)$ & $1.16(0.74-1.81)$ & \\
\hline $50-59$ & 323 & $274(85 \%)$ & $49(15 \%)$ & 1 & 1 & \\
\hline $60-69$ & 226 & $190(84 \%)$ & $36(16 \%)$ & $0.94(0.59-1.51)$ & $0.97(0.60-1.58)$ & \\
\hline \multicolumn{7}{|l|}{ Ethnicity } \\
\hline European & 912 & 766 (84\%) & $146(16 \%)$ & 1 & 1 & 0.02 \\
\hline Māori & 166 & $125(75 \%)$ & 41 (25\%) & $0.58(0.39-0.86)$ & $0.56(0.36-0.86)$ & \\
\hline Pacific & 122 & 94 (77\%) & $28(23 \%)$ & $0.64(0.41-1.01)$ & $0.55(0.33-0.91)$ & \\
\hline Others & 125 & $109(87 \%)$ & $16(13 \%)$ & $1.30(0.75-2.26)$ & $0.88(0.49-1.58)$ & \\
\hline \multicolumn{7}{|l|}{ Urban/Rural } \\
\hline Urban & 1155 & $968(84 \%)$ & $187(16 \%)$ & 1 & 1 & 0.2 \\
\hline Rural & 170 & $126(74 \%)$ & 44 (26\%) & $0.55(0.38-0.81)$ & $0.71(0.44-1.14)$ & \\
\hline \multicolumn{7}{|l|}{ Public/Private } \\
\hline Public & 900 & 710 (79\%) & 190 (21\%) & 1 & 1 & 0.005 \\
\hline Private & 425 & $384(90 \%)$ & $41(10 \%)$ & $2.51(1.75-3.59)$ & $1.74(1.18-2.57)$ & \\
\hline \multicolumn{7}{|l|}{ Register } \\
\hline Auckland & 1014 & $853(84 \%)$ & $161(16 \%)$ & 1 & 1 & 0.3 \\
\hline Waikato & 311 & $241(77 \%)$ & $70(23 \%)$ & $0.65(0.47-0.89)$ & $0.79(0.52-1.21)$ & \\
\hline
\end{tabular}


Grade

1 (well-differentiated)

$91 \quad 71(78 \%)$

$20(22 \%)$

1

2 (moderately-differentiated)

539 (84\%)

$103(16 \%)$

$1.47(0.86-2.53)$

1

0.5

3 (poorly-differentiated)

$484(82 \%)$

108 (18\%)

$1.26(0.74-2.16)$

$1.44(0.80-2.59)$

Missing/Unknown

$1.43(0.77-2.64)$

\section{Histology}

Ductal

Lobular

Others

830 (81\%)

190 (19\%)

32 (13\%)

$1.51(1.01-2.26)$

$1.35(0.65-2.78)$

$1.20(0.75-1.90)$

53 (85\%)

9 (15\%)

$1.66(0.75-3.67)$

\section{ER/PR Status}

ER/PR Both positive

ER or PR positive

ER/PR both negative

$672(85 \%)$

$116(15 \%)$

$48(22 \%)$

1

$0.62(0.43-0.90)$

$0.64(0.46-0.90)$

0.67 (0.45-1.01)

250 (79\%)

67 (21\%)

$0.68(0.46-1.00)$

\section{C3 index}

0 (no comorbid conditions)

999

860 (86\%)

139 (14\%)

1

2

3 (maximum)

$93 \quad 80(86 \%) \quad 13(14 \%) \quad 1.00(0.54-1.84)$

$93 \quad 80(86 \%) \quad 13(14 \%) \quad 1.00(0.54-1.84)$

$62 \quad 40(65 \%) \quad 22(35 \%)$

$0.29(0.17-0.51)$

$56(60 \%) \quad 37(40 \%)$

$0.25(0.16-0.39)$

Missing/Unknown

$58(74 \%)$

$20(26 \%)$

Multivariate analysis- adjusted for all variables in the table including year of diagnosis.

ER indicates oestrogen receptor; PR, progesterone receptor; 95\% CI, 95\% Confidence interval.

Note: Regarding C3 index, linkage to the hospital discharge data was done only for patients registered 2000 onward which resulted in high number of missing values in C3 index

it was not included in the multivariate analysis. 
Table 3 Comparison of adjusted odds ratios for breast cancer patients registered from 2000, with the whole cohort

\begin{tabular}{|c|c|c|c|c|c|c|c|c|}
\hline \multirow{3}{*}{ Factors } & \multicolumn{2}{|r|}{ From 1991} & \multicolumn{2}{|r|}{ From 2010} & \multicolumn{2}{|r|}{ From 1991} & \multicolumn{2}{|r|}{ From 2010} \\
\hline & \multicolumn{2}{|c|}{$\begin{array}{l}\text { Stage II and III patients registered } \\
\text { from } 1991(n=1455)\end{array}$} & \multicolumn{2}{|c|}{$\begin{array}{l}\text { Stage II and III patients registered } \\
\text { from } 2010(n=422)\end{array}$} & \multicolumn{2}{|c|}{$\begin{array}{l}\text { Stage III patients registered from } \\
\qquad 1991(n=1325)\end{array}$} & \multicolumn{2}{|c|}{$\begin{array}{l}\text { Stage III patients registered from } \\
\qquad 2010(n=377)\end{array}$} \\
\hline & Number & Adjusted OR (95\% CI) & Number & Adjusted OR (95\% CI) & Number & Adjusted OR (95\% CI) & Number & Adjusted OR (95\% CI) \\
\hline \multicolumn{9}{|l|}{ Age Group } \\
\hline$<40$ & 176 & $1.56(0.89-2.73)$ & 39 & $2.72(0.67-10.99)$ & 168 & $1.46(0.83-2.59)$ & 38 & $2.79(0.66-11.82)$ \\
\hline $40-49$ & 408 & $1.20(0.79-1.83)$ & 129 & $1.82(0.75-4.41)$ & 367 & $1.16(0.74-1.81)$ & 113 & $1.83(0.69-4.83)$ \\
\hline $50-59$ & 350 & 1 & 94 & 1 & 323 & 1 & 85 & 1 \\
\hline $60-69$ & 247 & $0.92(0.59-1.45)$ & 82 & $1.46(0.54-3.96)$ & 226 & $0.97(0.60-1.58)$ & 72 & $1.61(0.53-4.93)$ \\
\hline $70-79$ & 164 & $0.67(0.41-1.09)$ & 41 & $0.96(0.29-3.20)$ & 143 & $0.65(0.38-1.10)$ & 35 & $0.70(0.20-2.41)$ \\
\hline $80+$ & 110 & $0.19(0.12-0.32)$ & 37 & $0.16(0.06-0.45)$ & 98 & $0.17(0.10-0.29)$ & 34 & $0.12(0.04-0.38)$ \\
\hline \multicolumn{9}{|l|}{ Ethnicity } \\
\hline European & 999 & 1 & 281 & 1 & 912 & 1 & 253 & 1 \\
\hline Māori & 181 & $0.60(0.40-0.91)$ & 46 & $0.56(0.21-1.54)$ & 166 & $0.56(0.36-0.86)$ & 40 & $0.40(0.13-1.18)$ \\
\hline Pacific & 132 & $0.58(0.36-0.95)$ & 49 & $0.59(0.21-1.67)$ & 122 & $0.55(0.33-0.91)$ & 44 & $0.47(0.15-1.47)$ \\
\hline Others & 143 & $1.15(0.64-2.04)$ & 46 & $0.53(0.19-1.49)$ & 125 & $0.88(0.49-1.58)$ & 40 & $0.37(0.13-1.10)$ \\
\hline \multicolumn{9}{|l|}{ NZ Deprivation Codes } \\
\hline $\begin{array}{l}\text { NZDep } 1 \text { to } 2 \text { (least } \\
\text { deprived) }\end{array}$ & 278 & 1 & 100 & 1 & 254 & 1 & 90 & 1 \\
\hline NZDep 3 to 6 & 517 & $0.59(0.37-0.96)$ & 153 & $1.08(0.42-2.73)$ & 472 & $0.52(0.31-0.88)$ & 136 & $1.00(0.37-2.73)$ \\
\hline $\begin{array}{l}\text { NZDep } 7 \text { to } 10 \text { (most } \\
\text { deprived) }\end{array}$ & 660 & $0.63(0.39-1.02)$ & 169 & $0.69(0.26-1.85)$ & 599 & $0.58(0.34-0.99)$ & 151 & $0.79(0.27-2.35)$ \\
\hline \multicolumn{9}{|l|}{ Urban/Rural } \\
\hline Urban & 1271 & 1 & 43 & 1 & 1155 & 1 & 340 & 1 \\
\hline Rural & 184 & $0.65(0.41-1.00)$ & 379 & $0.29(0.10-0.82)$ & 170 & $0.71(0.44-1.14)$ & 37 & $0.30(0.10-0.94)$ \\
\hline \multicolumn{9}{|l|}{ Public/Private } \\
\hline Public & 987 & 1 & 275 & 1 & 900 & 1 & 245 & 1 \\
\hline Private & 468 & $1.73(1.20-2.49)$ & 147 & $1.36(0.61-3.07)$ & 425 & $1.74(1.18-2.57)$ & 132 & $1.52(0.63-3.71)$ \\
\hline
\end{tabular}




\begin{tabular}{|c|c|c|c|c|c|c|c|c|}
\hline Auckland & 1109 & 1 & 351 & 1 & 1014 & 1 & 316 & 1 \\
\hline Waikato & 346 & $0.93(0.63-1.38)$ & 71 & $2.11(0.70-6.33)$ & 311 & $0.79(0.52-1.21)$ & 61 & $1.69(0.53-5.43)$ \\
\hline II & 130 & 0.74 (0.46-1.19) & 45 & $1.28(0.46-3.57)$ & & & & \\
\hline \multicolumn{9}{|l|}{ Grade } \\
\hline 1 (well-differentiated) & 109 & 1 & 32 & 1 & 91 & 1 & 23 & 1 \\
\hline 2 (moderately-differentiated) & 704 & $1.60(0.95-2.70)$ & 210 & $1.70(0.53-5.45)$ & 642 & $1.44(0.80-2.59)$ & 188 & $1.76(0.43-7.22)$ \\
\hline Ductal & 1081 & 1 & 301 & 1 & 1020 & 1 & 284 & 1 \\
\hline Lobular & 292 & $1.16(0.76-1.79)$ & 97 & $0.51(0.22-1.19)$ & 243 & $1.20(0.75-1.90)$ & 74 & $0.48(0.19-1.18)$ \\
\hline Others & 82 & $1.08(0.59-2.00)$ & 24 & $1.26(0.25-6.35)$ & 62 & $1.66(0.75-3.67)$ & 19 & $1.56(0.18-13.5)$ \\
\hline \multicolumn{9}{|l|}{ ER/PR Status } \\
\hline ER/PR Both positive & 867 & 1 & 282 & 1 & 788 & 1 & 249 & 1 \\
\hline 1 & 101 & & 37 & $2.37(0.64-8.82)$ & 93 & & 34 & 1 \\
\hline 2 & 68 & & 21 & $1.02(0.28-3.76)$ & 62 & & 20 & 1 \\
\hline 3 (maximum) & 101 & & 27 & $0.68(0.23-2.06)$ & 93 & & 23 & $0.29(0.07-1.19)$ \\
\hline Missing/Unknown & 83 & & & & 78 & & & \\
\hline
\end{tabular}

Adjusted ORs - adjusted for other variables in the table including year of diagnosis

ER indicates oestrogen receptor; PR, progesterone receptor; 95\% CI, 95\% Confidence interval.

Note: Regarding C3 index, linkage to the hospital discharge data was done only for patients registered 2000 onward. 